\title{
Display Blindness: The Effect of Expectations on Attention towards Digital Signage
}

\author{
Jörg Müller ${ }^{1}$, Dennis Wilmsmann ${ }^{1}$, Juliane Exeler ${ }^{1}$, Markus Buzeck $^{1}$, Albrecht \\ Schmidt $^{2}$, Tim $\mathrm{Jay}^{3}$, and Antonio Krüger ${ }^{1}$ \\ ${ }^{1}$ University of Münster, ${ }^{2}$ University of Duisburg-Essen, ${ }^{3}$ University of Bristol
}

\begin{abstract}
In this paper we show how audience expectations towards what is presented on public displays can correlate with their attention towards these displays. Similar to the effect of Banner Blindness on the Web, displays for which users expect uninteresting content (e.g. advertisements) are often ignored. We investigate this effect in two studies. In the first, interviews with 91 users at 11 different public displays revealed that for most public displays, the audience expects boring advertisements and so ignores the displays. This was exemplified by the inclusion of two of our own displays. One, the iDisplay, which showed information for students, was looked at more often than the other (MobiDiC) which showed coupons for shops. In a second study, we conducted repertory grid interviews with 17 users to identify the dimensions that users believe to influence whether they look at public displays. We propose possible solutions to overcome this "Display Blindness" and increase audience attention towards public displays.
\end{abstract}

\section{Introduction}

Due to continuously falling display prices, digital displays have started to be installed in many public spaces. Deployers of such technology often assume that public displays inherently attract attention and therefore that people will look at them. We had similar expectations when we deployed two different public display networks. We noticed that the iDisplays[8] network, installed at the university and showing information for students, received a fair amount of attention. By contrast, the MobiDiC[7] network installed in the city center and showing coupons for nearby shops, received much less attention. Huang et al. have shown that indeed most public displays are ignored by many users or receive only very few glances[4]. Despite the fact that this effect has been well established, explanations for this behaviour are still lacking.

In other areas, lack of attention for aspects of the environment has been explained by the fact that attention is highly selective. The world provides far too much information to be processed by an individual. This is especially true for urban environments, where Milgram[6] showed that many individuals experience information overload. Milgram identified six common reactions to information overload, among them the allocation of less time to each input and disregard of low-priority inputs. In their survey on information overload, Eppler 
and Mengis[2] define the concept as follows: "Information overload describes the situation when too much information affects a person and the person is unable to recognize, understand or handle this amount of information." They conclude that when information supply exceeds information-processing capacity, a person has difficulties in identifying relevant information. He/she becomes highly selective and ignores large amounts of information, has difficulties in identifying relationships between details and overall perspective and needs more time to reach a decision.

One prominent example of such "disregard of low-priority inputs" has become known in the Web as "Banner Blindness". Burke et al.[1] have shown with eyetracking experiments that people rarely look directly at banners and show low recall for banner content. They conclude that "Participants in the present studies had an overriding incentive not to look at banners, and no amount of banner manipulation increased their pull. Longer exposure time, animation, and the presence of images did not make the task irrelevant ads more conspicuous. Connecting advertising to viewers goals may make ads more successful". In other words, people expected banners to lack task relevance and so ignored these areas.

In this paper, we pose the question of whether the effect of selective attention observed on the Web also applies to digital signage. In other words: What is the role of audience expectations regarding audience attention towards digital signage?

\section{Study 1: A Comparison of Looking Behaviour at Public Displays}

In order to investigate reasons why people look at public displays or not, we conducted interviews with people who passed by public displays. This provided us the ability to study both users and non-users of the technology in an ecologically valid setting.

\section{$2.1 \quad$ Method}

We created a corpus of all public displays we could find in the city of Münster, Germany. From these, we selected 11 different public display locations which we considered to provide a representative sample. These included three of our own iDisplays (two in front of lecture halls and one in the lobby of a university building) and one MobiDiC display installed in public telephones (see Figure 1). Others were located in shop windows (in a passageway, a mobile phone store and a credit store). Three displays showed television programs; one in a bank, one in a café and one in the waiting area of the citizen bureau. One was installed in a clothes store, showing fashion videos. Interviews were conducted on weekdays as well as weekends, between 9 am and $8 \mathrm{pm}$. Participants were selected on an opportunity basis, irrespective of gender, age (approx. 14-80 years) or other variables. In total 91 interviews were conducted. The procedure was as follows: 
Table 1. Summary of interview results. It is shown how many participants stated to have seen the display, what they expected to be shown there and whether they consider the content they expect interesting.

\begin{tabular}{|l|l|l|l|l|}
\hline Location & $\mathbf{N}$ & Looked & Expectations & Interesting \\
\hline $\begin{array}{l}\text { iDisplay Small } \\
\text { Lecture Hall }\end{array}$ & 15 & 15 & Content known (15) & 13 \\
$\begin{array}{l}\text { iDisplay Big } \\
\text { Lecture Hall }\end{array}$ & 15 & 13 & Content known (13) & 12 \\
\hline $\begin{array}{l}\text { iDisplay En- } \\
\text { trance }\end{array}$ & 6 & 6 & Content known (6) & 5 \\
\hline Citizen Bureau & 10 & 10 & Content known (10) & 8 \\
\hline MobiDiC & 10 & 0 & $\begin{array}{l}\text { Advertising (5), Phone book (2), Telekom Information } \\
\text { (2), City Information (1), City Map (1), Events (1), In- } \\
\text { ternet (1), Manual (1), Emergency Numbers (1) }\end{array}$ & 0 \\
\hline Shopping Mall & 6 & 0 & Ads for Fashion store nearby (5), Fashion (3), Videos (1) & 0 \\
\hline Cafe & 2 & 0 & Soccer (1), Ads (1), News (1) & 0 \\
\hline Credit Shop & 11 & 0 & $\begin{array}{l}\text { Ads for credit shop (5), Credit conditions (4), Tempera- } \\
\text { ture (1), Time (1), Television (1), Ads for Cosmetics (1) }\end{array}$ & 0 \\
\hline Bank & 2 & 1 & Ads (1), Special offers (1) & 0 \\
\hline Phone Shop & 9 & 2 & Ads for Telephones (9) & 0 \\
\hline Clothes Shop & 5 & 0 & Fashion (2), Music Videos (1), Ads (1) & \\
\hline
\end{tabular}

First we let participants pass the displays and observed whether they looked at them. After they passed the display, we stopped them in a position where they could see the display but not the content shown. We showed them the display and asked whether they had seen it. Next, we asked what they expected the display showed right now. We then asked whether what they expected would be interesting to them. Finally, we asked what they would like the displays to show at that very moment.
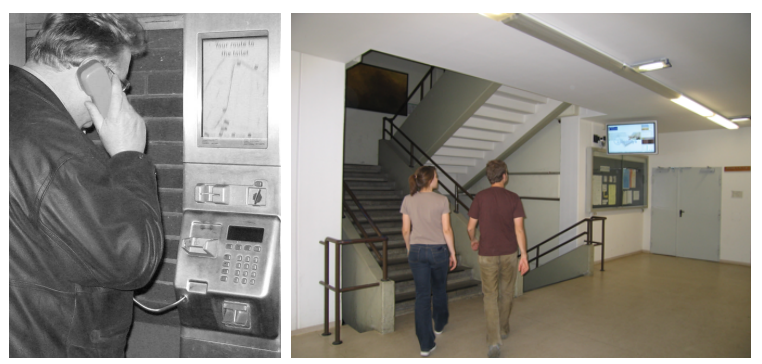

Fig. 1. The MobiDiC and iDisplays displays.

\subsection{Results}

The results of the interviews (shown in Table 1) showed that, for the iDisplays and the citizen bureau, most participants said they had seen the displays, knew the content and considered the content to be interesting to them. For the other displays, relatively few participants said they had seen them; many expected 
advertisements to be shown and not one participant considered the expected content to be interesting for them. Some typical statements were: "You know, everything here is so full of advertisements, I don't look at these things anymore." (an older lady). A younger woman said "No, I'm not interested in technology. I don't look at displays." One younger man said: "I don't have time to look there. You got ads everywhere, I just ignore them." What kind of advertisements participants expected depended strongly on the context. Most participants tried to guess who the display owner was (the telecommunications company for the MobiDiC displays, and the shop for displays installed in shop windows) and expected that the displays would show advertisements for the display owner. No participant expected any of the displays to show general ads for different advertisers. Finally, we asked participants what they would like to see on the displays. For the citizen bureau and the iDisplays, 3 participants (7\%) would like to see information on the building. At the iDisplays, 7 (19\%) participants would like to see information about events at the university. For the other displays, $15(45 \%)$ participants would like local information about the city, and 10 participants (30\%) would like current (local) news. 5 (15\%) participants would like to see sports news (e.g. football results) and $4(12 \%)$ participants would like entertainment content and lifestyle news. Two $(6 \%)$ would like to see the current temperature, and two would like advertisements. Two participants suggested that it would be best to turn off the displays.

From the interviews, two major factors seemed to affect whether participants looked at public displays. The comparison between the display in the citizen bureau and the café (which showed the same television channel) showed that displays where people wait and have nothing else to do received a lot more attention. A comparison between the iDisplays and the other displays showed that displays where participants expected something interesting (for them) received a lot of attention (in various locations). Displays where the participants expected nothing interesting on the other hand (like the MobiDiC displays and others) were largely ignored. Interestingly, the content that participants would have liked to have seen on public displays and what they expected seem to be diametrically opposed. While they would like to have seen local information and news, sports and lifestyle news as well as entertainment, they expected only advertisements to be shown. Another interesting observation was that while expectations were quite homogenous (ads), different people indicated they wanted to see very different content, implying it might make sense to personalize the content.

\section{Study 2: Directions for Further Research on Top-Down and Bottom-Up Effects on Attention}

After identifying the correlation of expectations with attention towards digital signage, we were interested in a broader view of potential factors that influence attention. We considered this would be useful both for placing the role of expectations in the context of other factors and for identifying promising areas for further research. To achieve this, we wanted to consider a corpus of very different 
signs, rather than investigate the impact of a few factors in detail. Therefore, we decided to study participants' responses to videos, showing a broad range of digital signs in the context of their surroundings. Using repertory grid interviews[5], it is possible to systematically elicit the dimensions that participants used to compare different digital signs. Using this method, each interview results in a number of dimensions used to compare different displays - these dimensions are then used by the participant to rate each display. In this case, Honey's content analysis[3] was used to analyse the grids, as this enables analysis of multiple grids (one from each participant) and comparisons of the importance of different dimensions by measuring the correlation of each dimension with the participants rating whether they would look at a display. The elicited dimensions are then categorized using affinity analysis[5] and for each category a mean correlation with the rating whether participants believe they would look at a display can be computed. This score can be used together with the number of dimensions in that category to estimate the relative importance of that category.

\subsection{Method}

We first collected videos (both our own and from YouTube) showing public displays including their surrounding context (e.g. people passing by, nearby buildings etc.), until no more videos dissimilar to those already in the corpus could be found. The resulting corpus contained 93 videos. A selection of these videos was then presented to a total of 17 participants on a computer screen. Seventeen participants were selected because the repertory grid technique dictates that one only adds participants until no new dimensions arise during the course of the interviews. The 17 people ( 7 female, 10 male, age 23-30 years) were selected among students of the institute and were not compensated for their participation.

In line with the repertory grid technique, each participant saw only a subset of the corpus. In this case, for each participant 10 videos were selected randomly and these were presented in random sets of three next to each other on a computer screen. For each group of three displays, participants were asked to state which two of them had something in common (emergent pole) that was different from the third (implicit pole). Exemplary poles were 'The display content is informative' versus 'The display content is not informative'. After providing a description, they were asked to rate each display from the 10 selected on a (5-point) Likert Scale on this new dimension. This process was repeated until no more dimensions arose. On average this occurred after 10 triples. Thus, each participant saw only 10 different videos but on average saw each video three times. At this point (when participants could not find any new dimensions), we asked them to rate each video on an additional, but key, dimension ' $I$ would always look at this display in this situation' versus 'I would never look at this display in this situation' (overall dimension).

We computed the correlation of all elicited dimensions to the corresponding overall rating of whether they would expect to look at the display or not. Finally, we used the bootstrapping technique[5] to group the dimensions into categories. Dimensions were categorized by two independent raters. Each dimension was 
picked from the stack and compared by similarity to all the existing categories. It was decided whether the dimension would fit any of the existing categories, if existing categories needed to be split, or if a new category should be created. This process was repeated until all dimensions were categorized. The categorizations of the two raters were then compared and discussed. Then, the raters repeated the categorization process, until over $90 \%$ similarity was reached. For each category, the mean \% similarity score (correlation to the overall likelihood that they would look) was then computed. Finally, the categories were sorted based on this value.

\section{$3.2 \quad$ Results}

Table 2. Factors that correlate with whether participants believe they would look at public displays as resulting from the Repertory Grid interviews. A high similarity score means the rating for dimensions in this category strongly correlates with whether participants expect to look at a display, a low score means it correlates only weakly.

\begin{tabular}{|c|c|c|c|}
\hline Category & Dimensions & $\mathbf{n}$ & $\begin{array}{l}\text { mean } \\
\% \operatorname{sim} .\end{array}$ \\
\hline $\begin{array}{l}\text { Conspicuity } \\
\text { of display and } \\
\text { content }\end{array}$ & $\begin{array}{l}\text { does not attract attention } \leftrightarrow \text { attracts attention }(90 \% \operatorname{sim} ., H), \\
\text { eye-catching } \leftrightarrow \text { simple }(65 \% \text { sim. }, H)\end{array}$ & 5 & 60 \\
\hline Colorful content & not so colorful $\leftrightarrow$ colorful $(75 \%$ sim.,H) & 3 & 56.67 \\
\hline $\begin{array}{l}\text { Interesting con- } \\
\text { tent }\end{array}$ & $\begin{array}{l}\text { interesting } \leftrightarrow \text { boring }(70 \% \text { sim. }, H) \text {, informative } \leftrightarrow \text { not informa- } \\
\text { tive }(40 \% \text { sim. }, \mathrm{I})\end{array}$ & 6 & 54.17 \\
\hline $\begin{array}{l}\text { Aesthetical con- } \\
\text { tent }\end{array}$ & $\begin{array}{l}\text { not attractive } \leftrightarrow \text { attractive }(65 \% \text { sim., H }) \text {, not so beautiful } \leftrightarrow \\
\text { beautiful }(60 \% \operatorname{sim} ., \mathrm{H}) \text {, dull, sterile } \leftrightarrow \text { aesthetic }(60 \% \text { sim., I })\end{array}$ & 9 & 42.78 \\
\hline $\begin{array}{l}\text { Emotional con- } \\
\text { tent }\end{array}$ & $\begin{array}{l}\text { not emotional appealing } \leftrightarrow \text { emotional appealing }(50 \% \operatorname{sim} ., \mathrm{H}), \\
\text { emotional content } \leftrightarrow \text { informative content }(40 \% \operatorname{sim} ., \mathrm{I})\end{array}$ & 3 & 40 \\
\hline $\begin{array}{l}\text { Long distance } \\
\text { visibility }\end{array}$ & \begin{tabular}{|l} 
visible on long \\
$(25 \%$ sim., $\mathrm{H})$
\end{tabular} & 2 & 40 \\
\hline $\begin{array}{l}\text { Content } \\
\text { adapted } \\
\text { context }\end{array}$ & $\begin{array}{l}\text { target audience undirected } \leftrightarrow \text { target } \text { audience directed } \\
(60 \% \text { sim.,I), differs from surrounding area } \leftrightarrow \text { fits to surround- } \\
\text { ing area }(45 \% \text { sim., } \mathrm{I}) \text {, isolated in surrounding area } \leftrightarrow \text { integrated } \\
\text { into surrounding area }(40 \% \text { sim., } \mathrm{I})\end{array}$ & 7 & 39.29 \\
\hline $\begin{array}{l}\text { Animated con- } \\
\text { tent }\end{array}$ & $\begin{array}{l}\text { animated } \leftrightarrow \text { static }(65 \% \operatorname{sim} ., \mathrm{H}), \text { fast content change } \leftrightarrow \text { slow } \\
\text { content change }(55 \% \operatorname{sim} ., \mathrm{H}), \text { dynamic content } \leftrightarrow \text { static content } \\
(55 \% \operatorname{sim} ., \mathrm{I})\end{array}$ & 14 & 37.5 \\
\hline Waiting area & $\begin{array}{l}\text { time to watch the display } \leftrightarrow \text { no time to watch the display } \\
(55 \% \text { sim., H), waiting in front of the display } \leftrightarrow \text { walking by the } \\
\text { display }(50 \% \text { sim.,I) }\end{array}$ & 4 & 36.25 \\
\hline Display size & large $\leftrightarrow$ small $(70 \%$ sim., $\mathrm{H})$ & 10 & 35,5 \\
\hline Type of content & $\begin{array}{l}\text { advertising } \leftrightarrow \text { entertainment }(60 \% \text { sim. }, H), \text { news } \leftrightarrow \text { video } \\
\text { game }(55 \% \text { sim., } \mathrm{H}), \text { news, commercials } \leftrightarrow \text { planning, design } \\
(45 \% \text { sim. }, \mathrm{H}), \text { advertising } \leftrightarrow \text { information system }(45 \% \text { sim., } \mathrm{H})\end{array}$ & 17 & 32.94 \\
\hline $\begin{array}{ll}\text { Different con- } \\
\text { tent }\end{array}$ & $\begin{array}{l}\text { varied content } \leftrightarrow \text { identical varied }(55 \% \text { sim., } \mathrm{H}), \text { varied commer- } \\
\text { cials } \leftrightarrow \text { single commercial }(35 \% \text { sim., } \mathrm{I})\end{array}$ & 6 & 32.5 \\
\hline
\end{tabular}

The results of the repertory grid study are depicted in Table 2 . In the first column, a descriptive name for the category, chosen by the raters, is given. In the second column, exemplary results are presented. The pole that correlated with the pole 'I would always look at the content' is printed in bold. Furthermore, the degree of correlation between this dimension and the overall dimension is given. In the third column, the number of dimensions in this category is given. In the 
fourth column, the mean similarity (correlation) of dimensions in this category to the overall dimension is presented. This mean similarity to the overall dimension can be interpreted as an indication of how strongly this category correlates to whether people expect to look at displays.

The first category simply describes the likelihood of looking and as such is not a "factor". Thus "colourfulness" (second row) is the most important factor we found influencing whether people thought they would look at the displays. The expectation of participants as to whether the content shown on the displays would be interesting comes in third. If participants expect interesting or informative content on the displays, they say they are more likely to look. The category "Content adapted to context" is somewhat ambiguous. Participants said they would be more likely to look at public displays if they appealed to the general public rather than to specific groups and did not agree whether they would look more if the display contrasted with surrounding context or if it was integrated with it.

\section{Discussion}

A limitation of Study 2 is that it only asked what people believed they would do, instead of determining what they would actually do, so these findings demand further research. As a next step, these factors should be validated in experiments to explore whether people's behaviour really reflects their stated beliefs in this context. As can be seen from Table 2, there are a range of factors associated with peoples' belief that they would look at a public display. These include bottomup factors like colourfulness or attractiveness of the display and, mentioned less often, the amount of time the display is potentially visible to a passer-by (mentioned as long distance visibility) and the size of the display. Other effects that have been mentioned in the literature, e.g. by Huang et al. [4], are the angle to walking direction, installation height, the distance of the display to a passerby and level of distraction (e.g. by other displays). Notably, however, whether participants expect interesting content seems to be more important than other effects that could be naively assumed, like the display size (which scores relatively low in this list). This is very much in line with the results from Study 1, where audience expectations strongly correlated with audience attention. Thus, we propose that in addition to bottom-up effects, top-down effects - audience expectations - need to be considered. The combination of the two studies indicates that for public displays people may expect nothing interesting and so do not look at them. People's expectations appear to depend on the perceived context; in particular who they believe the display owner is. For certain owners (e.g. the university, the citizen bureau) people expect the content to be interesting, while for others (e.g. shops) they expect advertisements. People would like to see content interesting to them, like local city information, local news, sports and entertainment content. It is likely that none of these bottom-up and top-down factors alone determines how much attention a display receives, but rather it is more likely that it is combination of these factors at play depending on the 
particular context. The influence of expectations is indeed similar to the effect of Banner Blindness. An interesting departure from this analogy is that while for Banner Blindness, increased colorfulness and animation do not increase attention[1], for displays, such bottom-up factors do appear to correlate with whether participants believe they will look at displays.

\section{Conclusion}

We can conclude that indeed the process of selective attention that is known from the Web also applies to digital signage. Thus, similar to the effect of "Banner Blindness", there is an effect of "Display Blindness" meaning that expectations of uninteresting content leads to a tendency to ignore displays. The relatively short time for which public displays have existed seems to have been sufficient to build such negative expectations for many passers-by. In order to avoid an "arms race" for the audience's attention, display owners should investigate audience expectations for certain displays and take them seriously. Content should be designed to fit these expectations, and if recognizable displays provide interesting content, it may even be possible to influence audience expectations over time. It should be kept in mind however that expectations are not the only effect to influence attention, but are embedded in a complex interplay of bottom-up and top-down factors.

\section{References}

1. M. Burke, A. Hornof, E. Nilsen, and N. Gorman. High-cost banner blindness: Ads increase perceived workload, hinder visual search, and are forgotten. ACM Trans. Comput.-Hum. Interact., 12(4):423-445, 2005.

2. M. J. Eppler and J. Mengis. The concept of information overload: A review of literature from organization science, accounting, marketing, mis, and related disciplines. The Information Society, 20:325 - 344, 2004.

3. P. Honey. The repertory grid in action. Industrial and Commercial Training, 11:452459, 1979 .

4. E. Huang, A. Koster, and J. Borchers. Overcoming assumptions and uncovering practices: When does the public really look at public displays? In Proc. of Pervasive 2008, 2008.

5. D. Jankowicz. The Easy Guide to Repertory Grids. Wiley, 1st edition, 2003.

6. S. Milgram. The experience of living in cities. Science, 13 March:1461-1468, 1970.

7. J. Müller and A. Krüger. How much to bid in digital signage advertising auctions? In Adjunct proceedings of Pervasive $200 \%$.

8. J. Müller, O. Paczkowski, and A. Krüger. Situated public news and reminder displays. In Proc. of European Conference on Ambient Intelligence, pages 248-265, 2007. 